ARTICLE

DOI: $10.1038 / s 41467-018-07488-0$

\title{
A synthetic microbial biosensor for high- throughput screening of lactam biocatalysts
}

Soo-Jin Yeom ${ }^{1}$, Moonjeong Kim¹,2, Kil Koang Kwon ${ }^{1}$, Yaoyao Fu' ${ }^{1}$ Eugene Rha ${ }^{1}$, Sung-Hyun Park ${ }^{1,3}$, Hyewon Lee ${ }^{1}$, Haseong Kim ${ }^{1,3}$, Dae-Hee Lee (1) 1,3, Dong-Myung Kim² \& Seung-Goo Lee ${ }^{1,3}$

Biocatalytic cyclization is highly desirable for efficient synthesis of biologically derived chemical substances, such as the commodity chemicals $\varepsilon$-caprolactam and $\delta$-valerolactam. To identify biocatalysts in lactam biosynthesis, we develop a caprolactam-detecting genetic enzyme screening system (CL-GESS). The Alcaligenes faecalis regulatory protein NitR is adopted for the highly specific detection of lactam compounds against lactam biosynthetic intermediates. We further systematically optimize the genetic components of the CL-GESS to enhance sensitivity, achieving 10-fold improvement. Using this highly sensitive GESS, we screen marine metagenomes and find an enzyme that cyclizes $\omega$-amino fatty acids to lactam. Moreover, we determine the $\mathrm{X}$-ray crystal structure and catalytic residues based on mutational analysis of the cyclase. The cyclase is also used as a helper enzyme to sense intracellular $\omega$-amino fatty acids. We expect this simple and accurate biosensor to have wideranging applications in rapid screening of new lactam-synthesizing enzymes and metabolic engineering for lactam bio-production.

\footnotetext{
${ }^{1}$ Synthetic Biology and Bioengineering Research Center, KRIBB, Daejeon 34141, Republic of Korea. ${ }^{2}$ Department of Chemical Engineering and Applied Chemistry, Chungnam National University, Daejeon 34134, Republic of Korea. ${ }^{3}$ Department of Biosystems and Bioengineering, KRIBB School of Biotechnology, University of Science and Technology, Daejeon 34113, Republic of Korea. Correspondence and requests for materials should be addressed to S.-G.L. (email: sglee@kribb.re.kr)
} 
dentifying biocatalysts, in particular, enzymes or pathways that play key roles in biosynthesis of non-native molecules of interest, is important to the industrial synthesis of chemical products. The discovery and engineering of enzymes or pathways involved in the synthesis of a desired product are often limited by a lack of sufficiently sensitive and rapid screening tools for the identification of candidate genes from large natural or synthetic gene libraries $^{1-3}$. Genetically encoded biosensors have untapped potential as tools for screening enzymes and pathways; thus, extensive efforts have been made to develop high-throughput screening (HTS) biosensors equipped with fluorescence-based genetic circuit devices. A key component in such devices is the ligand-inducible transcription factor (TF). In nature, a wide variety of TFs can specifically recognize small molecules and alter gene transcription at their targeted promoters. Numerous TFbased biosensors with ligand specificity and dynamic detection ranges are already available for sensing various small molecules ${ }^{4}$. Such biosensors are straightforward and powerful tools for detecting target molecules or their intermediates in investigations of enzymes and biosynthesis pathways ${ }^{5-9}$. Recently, many efforts using TF-based sensors in HTS have focused on altering TF specificities or sensitivities ${ }^{1}$. For instance, AraC of Escherichia coli, which originally senses arabinose, was engineered to detect mevalonate-a key intermediate of isoprenoid pathways-which enabled the screening of cells with increased mevalonate synthesis ${ }^{10}$.

Lactams are industrially important chemicals that are used in polyamide production ${ }^{11,12}$. $\delta$-Valerolactam and $\varepsilon$-caprolactam (CL) are converted from $\omega$-amino fatty acids (5-aminovaleric acid (5-AVA) or 6-aminocaproic acid (6-ACA)) and are used as precursors for the production of nylon-5, nylon- 6 , and nylon-6,5, which are used to manufacture tire cords, carpeting, plastics, and food-packaging materials ${ }^{13}$. $\varepsilon$-Caprolactam is most widely used to produce nylon- 6 and is mainly produced through Beckmann rearrangement of the cyclohexanone oxime in the presence of fuming sulfuric acid, at $90-120^{\circ} \mathrm{C}$. Biorenewable routes towards $\varepsilon$-caprolactam from fermentation-derived lysine, muconic acid, adipic acid, and 6-ACA have been discussed ${ }^{14}$. Additionally, the production of 6-ACA by direct fermentation of glucose has also been reported ${ }^{15}$.

Although several $\omega$-amino fatty acids are biologically produced through biosynthetic pathways, complete biosynthetic pathways capable of synthesizing lactams are mostly unknown owing to the lack of enzymes able to catalyze the last ring-cyclization step. To date, only two enzymes that can be used for lactam biosynthesis have been reported to carry out this step: Candida antarctica lipase B (CALB) ${ }^{16}$ and Streptomyces aizunensis acyl-CoA ligase $(\mathrm{ACL})^{10}$. However, CALB requires an anhydrous condition, high temperature, and long reaction time; thus, it is not suitable for lactam biosynthesis. ACL exhibits a broad substrate spectrum and has been used for cyclizing 4-aminobutyric acid, 5-AVA, and 6ACA into $\gamma$-butyrolactam, $\delta$-valerolactam, and $\varepsilon$-caprolactam, respectively ${ }^{11}$. Both 6 -ACA and its cyclized form, $\varepsilon$-caprolactam, are non-natural compounds; a previous report designed and proposed two biosynthetic pathways for fermentative production of $6-\mathrm{ACA}^{15}$. However, there is a lack of efficient and specific enzymes capable of producing $\varepsilon$-caprolactam from 6-ACA through enzymatic conversion and microbial fermentation.

In this study, we aim to investigate the lactam biosynthesis pathway in greater detail through the identification of certain enzymes involved, using HTS biosensors. To this end, we firstly designed and engineered a lactam-detecting biosensor, termed caprolactam-detectable genetic enzyme-screening system (CLGESS), and then carried out HTS of $\varepsilon$-caprolactam-converting cyclases from diverse metagenomes. To improve the signal-tonoise ratio and sensing sensitivity, a transcriptional regulator,
NitR, is engineered and used in the CL-GESS to identify a cyclase for $\varepsilon$-caprolactam or valerolactam biosynthesis from 6-ACA or 5AVA, respectively. Finally, we determined the X-ray crystal structure of the newly identified cyclase to provide insight into its cyclization activities. Using the cyclase, we developed a genetically encoded biosensor to sense $\omega$-amino fatty acids (5-ACA or 6AVA). We presented a cyclase that converts 6-ACA to $\varepsilon$-caprolactam, which will open opportunities for the development of a bioprocess to produce lactams and nylons.

\section{Results}

Design and construction of a lactam biosensor. The experimental strategy used to develop the CL-GESS is illustrated in Fig. 1. Our strategy included (a) engineering of a transcriptional regulator by fluorescence-activated cell sorting (FACS), (b) combinatorial analysis and optimization of a promoter or ribosomal-binding site (RBS) for controlling a regulator, (c) searching for a binding site on the regulator, and (d) optimization of a reporter gene. To develop a biosensor that responds to $\varepsilon$ caprolactam, we selected lactam-responsive TFs in nature and integrated them into a genetic circuit. In the actinomycete Rhodococcus rhodochrous $\mathrm{J}^{17-19}$ which is used in the industrial production of acrylamide and nicotinamide, nitrilase is strongly induced in the presence of $\varepsilon$-caprolactam ${ }^{19}$. In $R$. rhodochrous, nitrilase is encoded by the nitA gene in the nitrile degradation operon, which is positively regulated by NitR, which is in turn activated by isovaleronitrile or $\varepsilon$-caprolactam ${ }^{17}$. As Alcaligenes faecalis JM3 also contains a nitrile degradation operon, we examined the applicability of the $A$. faecalis nitR regulatory subunit (nitrile degradation operon) in the development of the CL-GESS by assessing the induction of nitA gene expression in the presence of various effector molecules. NitR responded solely to $\varepsilon$-caprolactam, which activated $n i t A$ gene expression (Supplementary Fig. 1). Based on this result, we transformed the nitR (E. coli codon-optimized) regulatory system of $A$. faecalis in the nitrile degradation operon and the nitA promoter $\left(\mathrm{P}_{\text {nitA }}\right)$ into $E$. coli to develop a synthetic CL-GESS for the specific detection of lactam (Fig. 1).

Optimization and characterization of the CL-GESS. We next optimized the CL-GESS to enhance its sensitivity. We constructed five different CL-GESSs in this study (Supplementary Fig. 2). The first, CL-GESSv1, contained the E. coli codon-optimized nitR gene under the control of a constitutive J23100 promoter in the direction opposite to that of transcription of the putative $\mathrm{P}_{\text {nitA(748) }}$ promoter-eGFP fusion (Supplementary Fig. 2). In a second plasmid, the eGFP reporter gene in CL-GESS (CL-GESSv1) was replaced with superfolder GFP (sfGFP) to produce CL-GESSv2. CL-GESSv2 showed higher fluorescence to all tested concentrations of $\varepsilon$-caprolactam than did CL-GESSv1 (0.5-50 mM, Fig. 2a). We further investigated the ability of the $\mathrm{P}_{\text {nitA }}$ region in CL-GESS to control a reporter, because we speculated that a strong promoter containing a NitR-binding site would be located close to the nitA gene. Initially, we used the 748-bp DNA fragment upstream of nitA as the putative $\mathrm{P}_{n i t A}$ to drive sfGFP expression in the CL-GESS plasmid, because the $\mathrm{P}_{\text {nitA }}$ region in genomic DNA had not yet been annotated. Additionally, there was no information on the binding of NitR to the $\mathrm{P}_{n i t A}$ region. One hundred-bp, 200-bp, or 300-bp truncations of the 748-bp $\mathrm{P}_{\text {nitA }}$ fragment from the RBS (T7RBS in this study) of the reporter gene were studied. Based on reporter experiments of the $\mathrm{P}_{\text {nita }}$ promoter fragments, $\mathrm{P}_{\text {nita }}$ was found to be located within $200 \mathrm{bp}$ from the RBS as CL-GESSv3 showed strong fluorescence (Supplementary Fig. 3a). 
The putative NitR-binding site was palindromically located in the -35 and untranslated regions of $\mathrm{P}_{\text {nitA }}$ (Supplementary Fig. 3b, c). It is important to note that sequences at positions -35 (TTCATC) and -10 (TACACT) upstream of the transcription start site were similar to the actinomycete (mainly streptomycete) consensus promoter sequence TTGAC(A/G)-17 bp-TAg(A/G) $(\mathrm{A} / \mathrm{G}) \mathrm{T}^{18}$. In addition, a single transcription initiation site was identified 74-bp upstream of the first ATG codon of GFP (Supplementary Fig. 3d). Deletion of NitR from the CL-GESS plasmid resulted in complete loss of $\mathrm{P}_{n i t A}$-induced green fluorescence (Supplementary Fig. 4), indicating that NitR activates the transcription of the target gene at its targeted promoter $\mathrm{P}_{\text {nitA }}$.

To further optimize NitR expression in CL-GESSv3, which contained sfGFP and truncated $\mathrm{P}_{\text {nitA }}$, we substituted the promoter and RBS with various synthetic promoters and RBSs of different strengths (rank order of promoter strength: J23100>J23106>J23114; rank order of RBS strength: B0030>B0034, and T7RBS) (http:// parts.igem.org/Promoters/Catalog/Anderson,

Supplementary Table 1). The plasmids CL-GESS J23114-B0034(CL-GESSv4) showed the highest fold change in fluorescence in the presence of $\varepsilon$-caprolactam (Fig. 2b).

To quantitatively assess the response of CL-GESSv4 to $\varepsilon$ caprolactam, we measured fluorescence at the single-cell level in E. coli DH5a cells harboring CL-GESSv4 in Luria-Bertani (LB) medium, at various $\varepsilon$-caprolactam concentrations (up to $30 \mathrm{mM}$ ). Fluorescence was observed only in the presence of $\varepsilon$-caprolactam
(Fig. 2c). The minimal concentration of $\varepsilon$-caprolactam required to activate NitR was $500 \mu \mathrm{M}$; moreover, a tight correlation was observed between fluorescence intensity and $\varepsilon$-caprolactam concentration. To examine the ligand specificity of CL-GESSv4, we applied it to various substrate and precursor molecules involved in lactam biosynthesis. CL-GESSv4 sensed $\varepsilon$-caprolactam, $\varepsilon$-caprolactone, cyclohexanone, $N$-acetylcaprolactam, $\delta$ valerolactam, $\delta$-valerolactone, benzonitrile, and isovaleronitrile, whereas detected none of the intermediates in the proposed $\varepsilon$ caprolactam biosynthesis pathway (Fig. 2d, Supplementary Fig. $7 \mathrm{a})$. Even at high concentrations $(30 \mathrm{mM})$, intermediates, such as L-lysine, 5-AVA, and 6-ACA did not induce sfGFP expression above the background level. To investigate the relationship between the intracellular $\varepsilon$-caprolactam level and sensor output, we measured intracellular $\varepsilon$-caprolactam. Intracellular $\varepsilon$ caprolactam was $0.035-0.27 \mu$ mole $/ \mathrm{mg}$ wet cells when we added 1-30 mM caprolactam extracellularly (Supplementary Table 2). As the concentration of external $\varepsilon$-caprolactam increased, the intracellular $\varepsilon$-caprolactam concentration also increased (Supplementary Table 2). When we washed the cells twice or three times with $50 \mathrm{ml}$ of saline, intracellular $\varepsilon$-caprolactam was not detected. These observations supported that the uptake and release of $\varepsilon$ caprolactam appear to be equilibrated by passive intracellular transport.

In addition, we evaluated the applicability of CL-GESSv4 to various Gram-negative bacteria, including Pseudomonas putida strains KT2440 and S12, and Ralstonia eutropha. The backbone
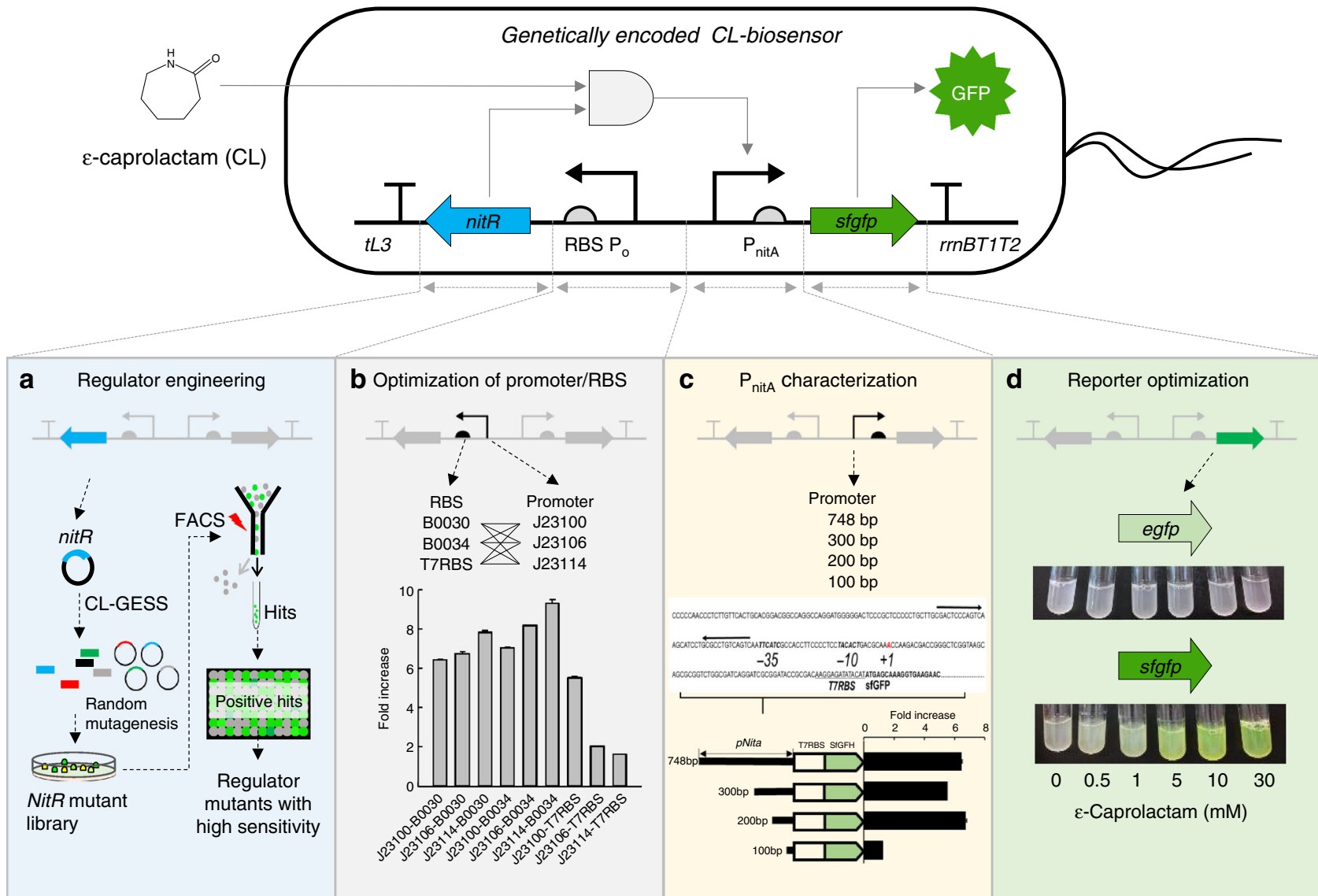

Modular approach for biosensor design

Fig. 1 Schematic representation of strategy for development of CL-GESS. $\varepsilon$-Caprolactam activates NitR derived from CL-GESS, which then activates the $P_{\text {nitA }}$ promoter and sfgfp gene expression in CL-GESS, resulting in fluorescence emission. a Schematic illustration of the screening procedure for engineering the NitR regulator by random mutagenesis. b Systematic combinatorial analysis and optimization of promoter and RBS for NitR expression. $\mathbf{c}$ Identification of the $P_{\text {nitA }}$ region by gene truncation. $\mathbf{d}$ Reporter change in CL-GESS 

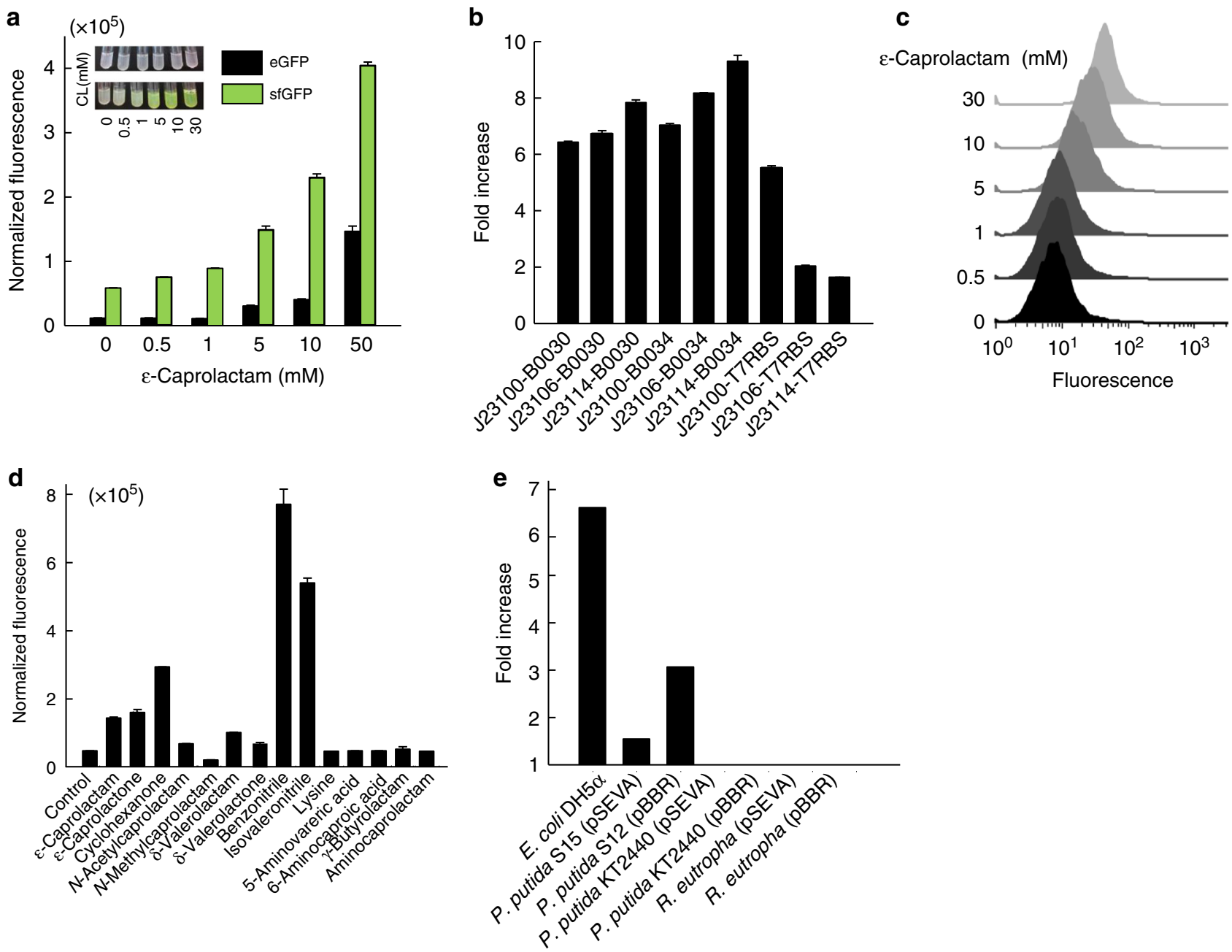

Fig. 2 Quantitative analysis of CL-GESS and CL-GESS variant responses. a Effect of reporter protein replacement in CL-GESS. b Promoter and RBS study of NitR expression in CL-GESS. Systematic combinatorial analysis and optimization of NitR expression was carried out using constitutive BioBrick promoters with known relative strength (http://parts.igem.org/Promoters/Catalog/Ecoli/Constitutive, Supplementary Fig. 2). Values represent means \pm SDs of three independent experiments. c Correlation between concentration of exogenous $\varepsilon$-caprolactam and specific fluorescence measured $16 \mathrm{~h}$ after addition of $\varepsilon$ caprolactam at the indicated concentrations to $E$. coli cells harboring CL-GESS. Representative histograms from three independent rounds of FACS are shown. $\mathbf{d}$ Ligand specificity of CL-GESS. Various lactam or lactone compounds were detectable at a concentration of $1 \mathrm{mM}$ by CL-GESS. Values represent means \pm SDs of three independent experiments. e Fluorescence signal of CL-GESS in various hosts. Values represent means \pm SDs of three independent experiments

vector of CL-GESSv4 was replaced with $\mathrm{pBBRBB}^{20}$ or pSEVA (http://seva.cnb.csic.es) containing RK2 or pBBR1 ori, respectively. $P$. putida S12 containing pBBRBB-based CLGESSv4 showed a three-fold increase in signal in the presence of $\varepsilon$-caprolactam, whereas S12 transformed with pSEVA-CLGESSv4 exhibited a 1.5-fold increase (Fig. 2e). P. putida KT2440 and $R$. eutropha harboring pBBRBB-based or pSEVA-based CLGESS showed no fluorescence response to $\varepsilon$-caprolactam (Fig. 2e). These result shows the possibility that CL-GESS system can be applied in $P$. putida with various advantages for natural product biosynthesis, such as a versatile intrinsic metabolism with diverse enzymatic capacities, and outstanding tolerance to xenobiotics ${ }^{21}$. For these reasons, the genetic circuit-based sensor in P. putida should be further studied.

Engineering the NitR TF. To improve the sensitivity of CLGESSv4 further, we engineered the NitR transcriptional regulator. To this end, we designed a single cell-based screening strategy for a library of NitR with random mutations. We selected hits with a high fluorescence signal in the presence of $\varepsilon$-caprolactam and removed false positives that exhibited fluorescence in the absence of $\varepsilon$-caprolactam. After three rounds of screening, the highest $0.5 \%$ of phenotypes were selected as putative hits and their fluorescence signals were verified against $\varepsilon$-caprolactam in liquid LB medium (Supplementary Fig. 5a). Among them, a NitR double


signal when exposed to $\varepsilon$-caprolactam at a low concentration of $50 \mu \mathrm{M}$ as minimum while wild-type CL-GESS showed increased fluorescence signal more than $500 \mu \mathrm{M}$ (Fig. 3a).

We further engineered the double mutant (CL-GESS NitR-L117F/ P133S) to maximize the sensor sensitivity. To find a mutation to generate NitR mutants more sensitive to $\varepsilon$-caprolactam, we firstly tested the P133 location. However, when we changed the P133 to serine, there was no change in sensitivity of CL-GESS to $\varepsilon$ caprolactam, but the background fluorescence was increased. The single-point mutant CL-GESS ${ }_{\mathrm{NitR}-\mathrm{L} 117 \mathrm{~F}}$ exhibited strong fluorescence in the presence of $\varepsilon$-caprolactam (Fig. 3b). Replacement of L117 in the NitR regulator with the non-polar aliphatic amino acid alanine or a charged polar amino acid, such as arginine or glutamate, abolished the ability of the CL-GESS to detect 


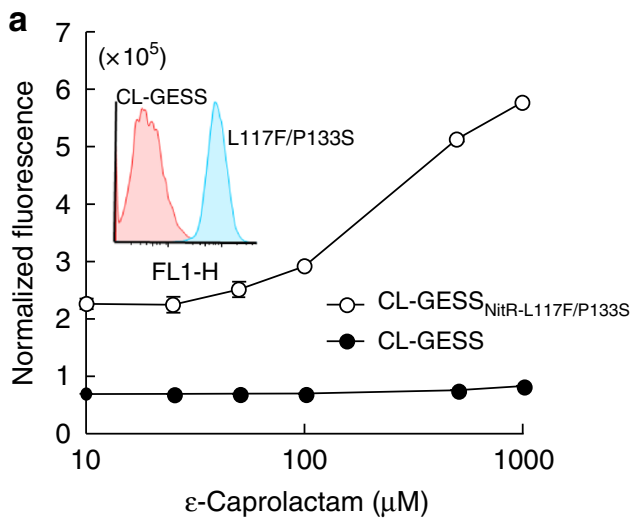

b
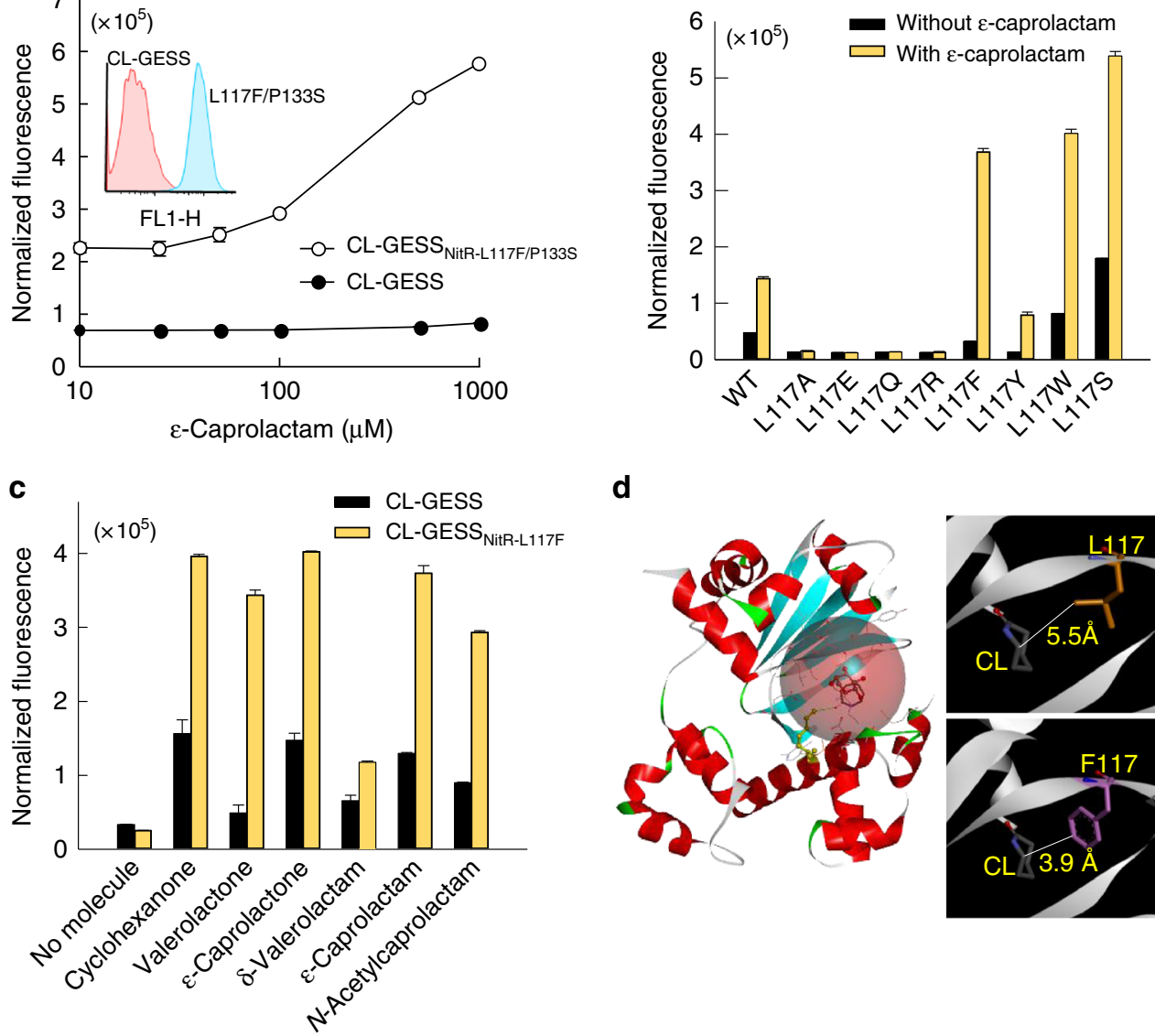

d

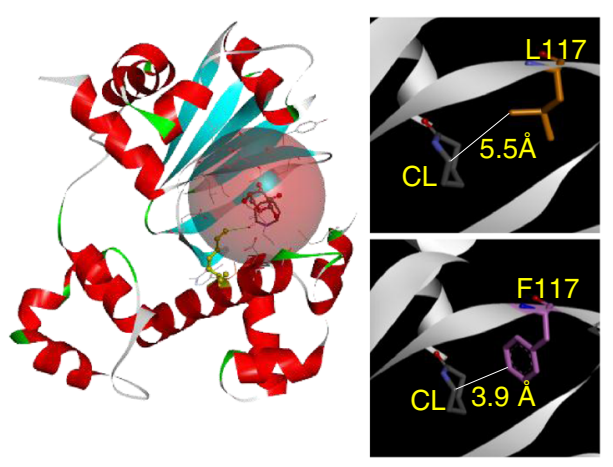

Fig. 3 Engineering of the NitR regulator. a Quantitative analysis of the response of CL-GESS and CL-GESS double mutant (S133P, L117F) to $\varepsilon$-caprolactam. b


modeling of CL-GESS and CL-GESS ${ }_{L 117 F}$. Values represent means \pm SDs of three independent experiments

$\varepsilon$-caprolactam (Fig. 3b). Interestingly, the substitution of L117 with aromatic residues, as in CL-GESS $\mathrm{NitR-L117F}_{\text {, CL-GESS }}$ NitRL117Y, and CL-GESS ${ }_{\mathrm{NitR}-\mathrm{L} 117 \mathrm{~W}}$, induced a marked increase in the fluorescence signal of 11.4-fold, 5.6-fold, and 4.9-fold, respectively, in the presence of $\varepsilon$-caprolactam as compared to the 3 -fold increase observed for wild-type CL-GESS (Fig. 3b). CL-GESS ${ }_{\mathrm{NitR}}$ L117F also showed enhanced fluorescence for cyclohexanone, $\delta$ valerolactone, $\varepsilon$-caprolactone, $\delta$-valerolactam, and $N$-acetylcapro-


was able to detect $\delta$-valerolactone, $\delta$-valerolactam, and $n$ acetylcaprolactam (Fig. 3c). CL-GESS ${ }_{\text {NitR-L117 }}$ variants (L117F, L117Y, and L117W) also yielded strong signals in the presence of various lactones or lactams rather than nitrile compounds (Supplementary Fig. 6). These results suggested that bulky aromatic residues in position 117 may interact with lactam or lactone substrates. To determine the amino acid residues of NitR that are important for the interaction with $\varepsilon$-caprolactam, a homology model of $A$. faecalis NitR was constructed based on the crystal structure of Vibrio cholerae O395 ToxT (Protein Data Bank (PBD) entry $3 \mathrm{GBG})^{22}$ as the closest sequence among the known structures of AraC-type regulators. Although the sequence identity between NitR and ToxT was relatively low $(18.1 \%$ identity, $38.2 \%$ similarity), the sequence identity (23\% identity, $43 \%$ similarity) of the $\mathrm{N}$-terminal domain (substrate-binding site) between two regulators can result in useful homology model. Molecular docking was attempted to estimate the substrate interactions in the A. faecalis NitR active site (Fig. $3 \mathrm{~d}$ ). Amino acid L117 of NitR was estimated to be located on one side of the active pocket (Fig. 3d) and the mutations to aromatic amino acids was estimated to result in a shorter distance between a docked $\varepsilon$ caprolactam and the aromatic side chains in mutant NitR (Fig. 3d). These results suggest that an aromatic amino acid at position 117 closely interacts with lactam or lactone substrates in the active pocket. Although the L117W mutant with larger side chains appeared more sensitive to $\varepsilon$-caprolactam (Supplementary Fig. 6), it also showed a higher background signal. Therefore, we used L117F mutant for the screening of $\varepsilon$-caprolactam producing enzymes because high background of L117W mutant could be a problem during the screening of large library.

HTS of a metagenome library using CL-GESS ${ }_{\text {NitR-L117F. A }}$ metagenome is a potentially substantial reservoir of valuable enzymes or biocatalysts that could be targeted by CL-GESS ${ }_{\mathrm{NitR}}$ L117F. Various intermediates in the $\varepsilon$-caprolactam synthesis pathway, including L-lysine, 5-AVA, and ACA did not induce sfGFP expression of CL-GESS ${ }_{\text {NitR-L117F }}$ in solid or liquid LB medium, suggesting that the highly sensitive CL-GESS ${ }_{\text {NitR-L117F }}$ can be used for HTS of new enzymes in the $\varepsilon$-caprolactam biosynthesis pathway (Supplementary Fig. 7). We carried out CLGESS-based HTS of a metagenomic fosmid library constructed using tidal flat sediments. To this end, we firstly transformed a plasmid encoding CL-GESS ${ }_{\mathrm{NitR}-\mathrm{L} 117 \mathrm{~F}}$ into $E$. coli cells to screen a cyclase that could convert 6 -ACA into $\varepsilon$-caprolactam. Cells grown in LB medium containing $10 \mathrm{mM}$ 6-ACA were sorted by flow cytometry. After removing false positives by culturing recovered cells in fresh LB medium without 6-ACA, a total of $10^{6}$ cells were 


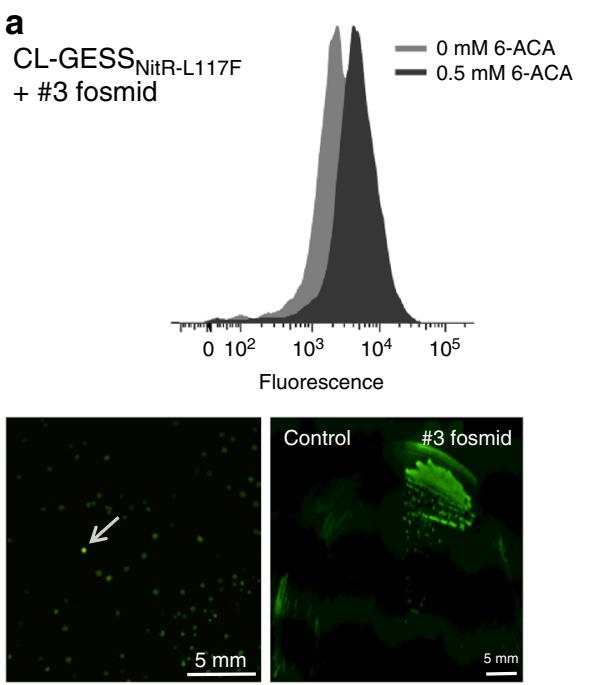

b

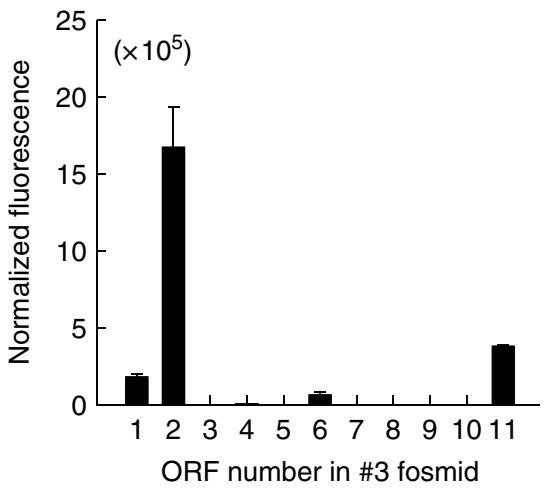


$\mu \mathrm{M}$ 6-ACA and selection of a strongly fluorescent colony (positive hit) on LB agar containing $10 \mathrm{mM} 6-\mathrm{ACA}$. The scale bar is $5 \mathrm{~mm}$. $\mathbf{b}$ Analysis of fluorescence in a clone with $11 \mathrm{ORFs}$ in pET28a(+) from a metagenomic fosmid using CL-GESS ${ }_{\text {L117F }}$ to assess $\varepsilon$-caprolactam-converting activity from 10 $\mathrm{mM} 6$-ACA over $24 \mathrm{~h}$. Values represent means \pm SDs of three independent experiments

obtained (Supplementary Fig. 5). These cells were cultured in LB medium containing $10 \mathrm{mM}$ 6-ACA and sorted again based on fluorescence intensity, yielding 27 hits showing stronger fluorescence on LB solid plate than the control. The 27 hits were grown on solid LB medium containing 6-ACA, and one colony (named fosmid \#3), with the strongest fluorescence, was selected by microscopy (Fig. 4a). Flow-cytometric analysis revealed that fosmid \#3 with CL-GESS ${ }_{\text {NitR-L117F }}$ exhibited stronger fluorescence in the presence of 6-ACA than did cells harboring the empty fosmid vector (Fig. 4a, Supplementary Fig. 8). This suggested that fosmid \#3 contained at least one open-reading frame (ORF) encoding an enzyme that catalyzed the biosynthesis of $\varepsilon$ caprolactam from 6-ACA. Therefore, we isolated DNA from fosmid \#3 cells, and then completely sequenced it using the shotgun method.

The DNA from fosmid \#3 contained a 31-kb DNA fragment that showed up to $88 \%$ identity to Citrobacter genome sequences (Supplementary Table 3). At least one ORF encoding a putative cyclase was identified, supporting the results of the functional screen. Of the 25 ORFs in clone \#3, we selected 11 ORFs that were up to $500 \mathrm{bp}$ (Supplementary Table 4) and subcloned them into the pET28a $(+)$ plasmid. E. coli cells containing CL-GESS ${ }_{\mathrm{NitR}}$ L117F were transformed with the pET28a $(+)$ plasmid encoding an individual ORF to detect the fluorescence signal corresponding to the conversion of 6-ACA to $\varepsilon$-caprolactam. We found that an ORF encoding 3-hydroxybutyrate dehydrogenase from Citrobacter freundii (CF3HBD) was positive for this activity (number 2 in Fig. 4b).

Characterization of CF3HBD. To corroborate its cyclase activity, CF3HBD was expressed and purified as a $27-\mathrm{kDa}$ protein (Supplementary Fig. 10a), and its cyclization activity was calibrated by detection of $\varepsilon$-caprolactam by liquid chromatography-mass spectrometry (LC-MS; Fig. 5a and Supplementary Fig. 9b) and nuclear magnetic resonance (NMR; Fig. 5b). Importantly, this reaction was performed using purified enzyme and in the absence of any cofactors, such as ATP and NADH. Furthermore, the reaction mixture was extracted with ethyl acetate to purify the reaction product from the other materials. LC-MS analysis revealed that the purity of the obtained caprolactam was $>99 \%$ (Supplementary Fig. 9a). Thus, based on the product confirmed by NMR, LC-MS, and IR (infrared spectroscopy) analyses, we concluded that the promiscuous enzyme catalyzed the cyclization of 6-ACA in the absence of any cofactor (Supplementary Fig. 9a, c, d). CF3HBD showed $81 \%, 82 \%, 81 \%, 56 \%$, and $28 \%$ sequence identity with $3 \mathrm{HBD}$ from Serratia marcescens, Klebsiella pneumoniae, Enterobacter sp., Rhodobacter sphaeroides, and Pseudomonas lemoignei, respectively (Supplementary Fig. 10b). We cloned two additional 3HBDs from S. marcescens (SM3HBD) and Enterobacter sp. (ES3HBD) and determined their cyclase activity after purification (Supplementary Fig. 10a) using 6-ACA as a substrate; both enzymes showed cyclization activity towards 6ACA to produce $\varepsilon$-caprolactam as well (Supplementary Fig. 10c). However, the 3 HBDs from $R$. sphaeroides and P. lemoignei, with low sequence identity, showed no cyclization activities.

Basically, the screened CF3HBDs belong to the NAD $(\mathrm{P}) \mathrm{H}$ dependent short-chain dehydrogenase family, and they have cyclization activity as unexpected promiscuous activity. D-3Hydroxybutyrate dehydrogenase catalyzed the reversible and stereospecific oxidation of D-3-hydroxybutyric acid to acetoacetate using $\mathrm{NAD}^{+}$as a coenzyme ${ }^{23}$. Thus, we further investigated simple enzyme characteristics in terms of the effects of $\mathrm{pH}$ and temperature, metals, and coenzymes on enzyme activities. The maximum dehydrogenation activity of CF3HBD towards 3hydroxybutyrate was observed at $\mathrm{pH} 8.0$ and at $40{ }^{\circ} \mathrm{C}$ (Supplementary Fig. 11a, b). The maximum cyclization activity of CF3HBD towards 3-hydroxybutyric acid was observed at $\mathrm{pH} 7.5$ and $40{ }^{\circ} \mathrm{C}$ (Supplementary Fig. 11a, b). The cyclization activity of $\mathrm{CF} 3 \mathrm{HBD}$ did not require metals or cofactors in vitro (Supplementary Fig. 12a, b). The time course analyses for the production of $\varepsilon$-caprolactam were conducted using $1 \mathrm{mM}$ 6-ACA and CF3HBD. The enzyme concentrations used were $0.1,0.25$, and $0.5 \mathrm{mg} / \mathrm{ml}$ and yielded molar conversions of $17.9 \%, 34.6 \%$, and $47.3 \%$, respectively (Supplementary Fig. 13). No detectable intermediate was obtained during this reaction. In addition, we found that CF3HBD could catalyze the degradation of the cyclic amide group in $\varepsilon$-caprolactam, generating 6 -ACA as a reaction product (Supplementary Fig. 14).

Crystal structure of the CF3HBD and homology modeling. To further characterize the cyclization activity, we determined the crystal structure of $\mathrm{CF} 3 \mathrm{HBD}$ in complex with $\mathrm{NAD}^{+}$at a 
a

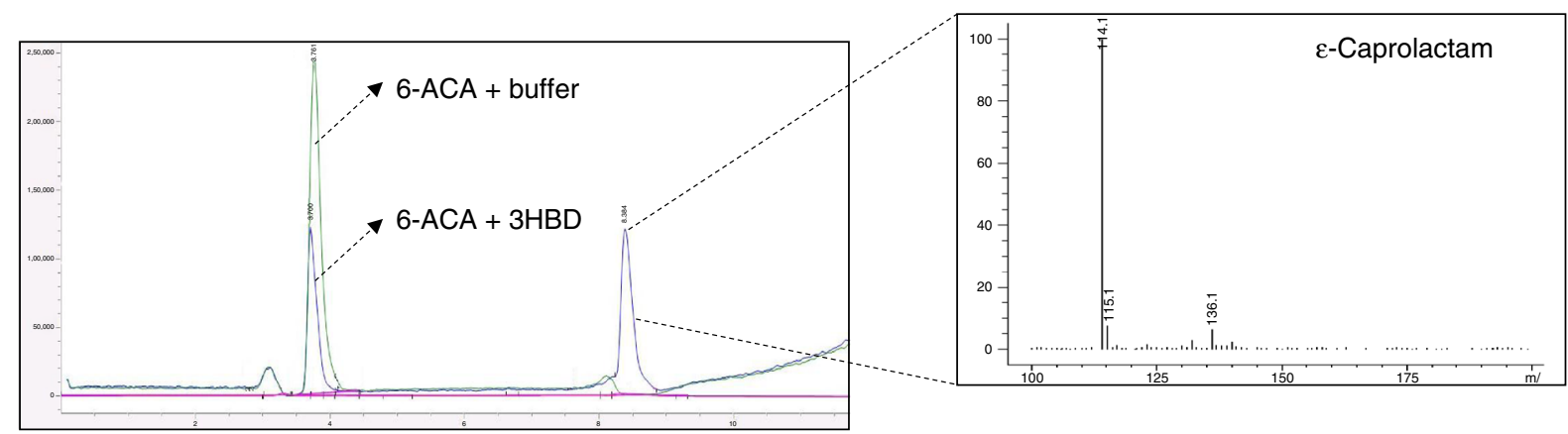

b

Product $(6-\mathrm{ACA}+3 \mathrm{HBD})$

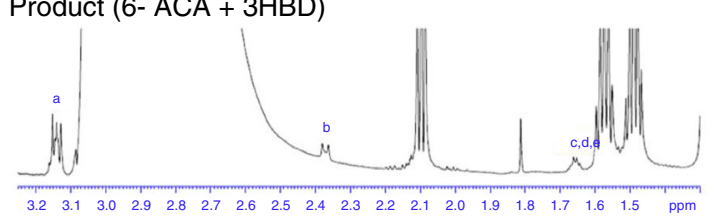

$\varepsilon$-caprolactam

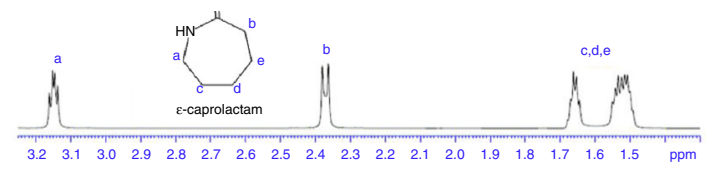

C $6-A C A$



Fig. 5 Cyclase activity. a LC-MS analysis and mass configuration of $\varepsilon$-caprolactam produced by CF3HBD from 6-ACA (blue peak) and 6-ACAwithout CF3HBD as a control (green peak). Analysis of the reaction mixture by LC-MS. The reaction was carried out using $0.5 \mathrm{mg} / \mathrm{ml}$ purified CF3HBD and $1 \mathrm{mM}$ 6-ACA as the substrate at $35^{\circ} \mathrm{C}$ with $50 \mathrm{mM} \mathrm{HEPES}$ buffer $(\mathrm{pH} \mathrm{7.5)} \mathrm{b} \mathrm{NMR} \mathrm{analysis} \mathrm{of} \mathrm{the} \mathrm{reaction} \mathrm{mixture} \mathrm{for} \mathrm{3HBD} \mathrm{in} \mathrm{the} \mathrm{presence} \mathrm{of} \mathrm{6-ACA.} \mathrm{The}$ reaction was carried out using $0.5 \mathrm{mg} / \mathrm{ml}$ purified CF3HBD and $1 \mathrm{mM} 6-\mathrm{ACA}$ as the substrate at $35^{\circ} \mathrm{C}$ with $50 \mathrm{mM} \mathrm{HEPES} \mathrm{buffer} \mathrm{(pH} \mathrm{7.5).} \mathrm{c} \mathrm{Schematic}$ representation of the ACA-GESS system consisting of CL-GESS and cyclase in $E$. coli. Intracellular $\varepsilon$-caprolactam compounds were generated by $3 \mathrm{HBD}$ from $\omega$-fatty acids, such as 5-AVA and 6-ACA, and were visualized by sfGFP, whose expression was induced by the $\varepsilon$-caprolactam-NitR complex

resolution of $2.29 \AA$ (Supplementary Fig. 15). We found that the asymmetric unit had a tetramer structure with two $\mathrm{NAD}^{+}$-free subunits (Fig. 6a). However, the crystal structure of CF3HBD in complex with $\varepsilon$-caprolactam or 6-ACA under various conditions could not obtain diffraction data. The crystal structure of the CF3HBD-NAD ${ }^{+}$complex was refined to an $R$ factor of $19.1 \%$ $\left(R_{\text {free }}=23.6 \%\right)$ for all data observed, without any cutoff in the resolution range 50-2.3. . A Ramachandran plot of the four polypeptides showed that all of the main-chain atoms fall within the allowed regions, with $96.1 \%$ of residues in the most favored regions and $3.6 \%$ of residues in additionally allowed regions. The refined structure was in good agreement with the X-ray crystallographic statistics for bond angles, bond lengths, and other geometric parameters (Table 1). Nearly all of the residues were well defined in the electron-density map, except the unidentified electron density located in the pocket near the nicotinamide group of $\mathrm{NAD}^{+}$, which corresponded to the active site of CF3HBD (Fig. 6b). Based on its position, this density could represent a molecule of $\varepsilon$-caprolactam transiently captured by the enzyme during crystal packing. Molecular docking of CF3HBD with 6-ACA and $\varepsilon$-caprolactam in the unidentified electron density was achieved using the holo form of CF3HBD (Fig. 6c, d). The affinities of 6 -ACA and $\varepsilon$-caprolactam to CF3HBD were -4.3 and $-3.7 \mathrm{kcal} / \mathrm{mol}$, respectively.

Determination of the active site residues by mutagenesis. To identify the catalytic residues involved in the dual activities of $\mathrm{CF} 3 \mathrm{HBD}$, we conducted a ligand-docking study of the linear form of 6-ACA with the crystal structure. The docking results suggested that 10 residues (Q91, S139, V140, H141, K149, Y152, Q193, W184, V190, and Q193) located within 4.0 A of the center of the docked substrate are active-site residues. These residues were selected as candidate determinant residues for enzyme activity. The selected 10 residues were separately replaced with alanine or glutamate, and the wild-type and all mutant 3HBD were expressed and purified by His tag affinity chromatography as a single band with a molecular mass of $\sim 27 \mathrm{kDa}$ in sodium dodecyl sulfate-polyacrylamide gel electrophoresis (SDS-PAGE) (Supplementary Fig. 16). Alanine substitution of the catalytic residues, such as Q91, S139, and H141 completely abolished catalytic activity towards both 3-hydroxybutyric acid and 6-ACA, which suggested that dehydrogenation activity and cyclization activity share catalytic site (Table 2). Alanine substitution at V140, Y152, and W184 resulted in lack of activity towards 3hydroxybutyric acid, whereas these mutants showed cyclization activities for 6-ACA of more than $80 \%$. Interestingly, the Y152A mutant showed the highest cyclization activity, with a three-fold increase, for 6-ACA. Thus, we determined the kinetic parameters using the Michaelis-Menten and Lineweaver-Burk plots of the wild-type and Y152A-mutant enzymes toward 6-ACA (Supplementary Fig. 17). The Y152A mutant had about 3.4-fold higher catalytic efficiency than that of wild-type enzyme (Table 3 ). This result suggested that an alanine residue may be preferred rather than the bulky aromatic amino acid to allow 6-ACA in the active site, but not 3-hydroxybutyric acid.

CL-GESS as a sensor for $\boldsymbol{\omega}$-amino fatty acid cyclization. We investigated whether CL-GESS ${ }_{\mathrm{L} 117 \mathrm{~F}}$ can be used as a biosensor that reflects the amount of $\varepsilon$-caprolactam formed from 6-ACA as a fluorescence signal detectable by flow cytometry (Fig. 5c). We co-transformed E. coli EPI(DE3) cells ${ }^{24}$ with the CL-GESS ${ }_{\mathrm{L} 117 \mathrm{~F}}$ sensor and the other plasmid expressing CF3HBD under the 
a

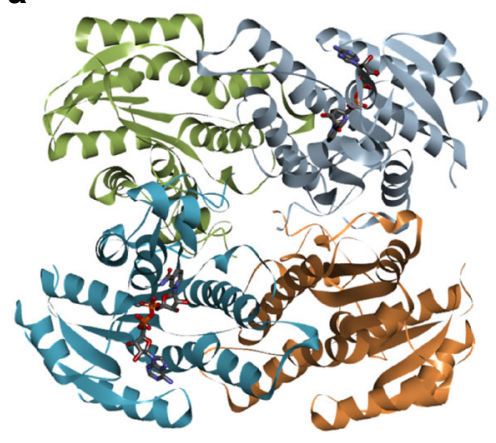

C



b



d



Fig. 6 Crystal structure and homology model of CF3HBD. a Overall structure of CF3HBD. b An electron density map for the active site region. Electron densities were contoured using COOT. Unknown molecule observed in the substrate-binding pocket. The $2 \mathrm{mFo}-\mathrm{DFc}$ electron density map is shown as a gray mesh contoured at $1.0 \sigma$. c Proposed model for 6-ACA-binding by CF3HBD. The ligand 6-ACA with an affinity of $-4.3 \mathrm{kcal} / \mathrm{mol}$ was docked in CF3HBD using AutoDock Vina. d Homology model of CF3HBD with $\varepsilon$-caprolactam (CL). The ligand $\mathrm{CL}$ with an affinity of $-3.7 \mathrm{kcal} / \mathrm{mol}$ was docked in $\mathrm{CF} 3 \mathrm{HBD}$ using AutoDock Vina. 6-ACA and $\varepsilon$-caprolactam molecules are shown as ball and stick models

control of the T7 promoter and lacI regulation. In cells harboring $\mathrm{CL}_{-G^{-}} \mathrm{SSS}_{\mathrm{L} 117 \mathrm{~F}}$ and CF3HBD which were termed ACA-GESS, strong fluorescence was observed in the presence of 5-AVA and 6-ACA (Supplementary Fig. 18). The CF3HBD enzyme can serve as a helper enzyme for substrate detection in the CL-GESS system.

\section{Discussion}

The identification of new enzymes or evolution of enzymes for desired activities is a crucial task for industrial biotechnology. TFbased genetic screening methods have received much attention as enzyme selection systems because they enable the rapid screening of libraries comprising innumerable genetic variants. We previously identified a phenolic compound with GESS, a reporter system that can be used to screen metagenomic or mutation libraries for enzymes ${ }^{3,25}$. Additionally, HTS for the generation of new activity or directed evolution by TF-based biosensor has been reported $^{26,27}$. The TF-based genetic screening method could be useful to generate new activity that would alleviate the current burden on HTS. In this report, we described the design and validation of CL-GESS, a genetically encoded biosensor for the screening and engineering of lactam synthesis enzymes. The engineering of NitR as a TF for higher sensitivity for screening was successful and helpful to screen for a cyclase that has promiscuous activity. We believe that this tool will enable the scientific community to study lactam biosynthesis and further develop an economical bioprocess for lactam production.

NitR is related to the bacterial XylS/AraC family of $\mathrm{TFs}^{17}$ that are involved in metabolism of carbon sources and have been linked to pathogenesis, with sequence similarity at the carboxyl terminus containing a helix-turn-helix DNA-binding motif ${ }^{28}$ Deletion of NitR resulted in the complete loss of $\mathrm{P}_{\text {nit } A}$-induced green fluorescence (Supplementary Fig. 4), indicating that NitR activates the transcription of the target gene in the operon. Using engineered NitR in the CL-GESS allowed us to detect target molecules with low background signal levels, which is a desirable feature for HTS systems. Single-cell technologies based on high signal-to-noise ratios have been used to explore cellular mechanisms $s^{29,30}$. We applied this strategy to the GESS, although there was a low background signal that was likely due to leaky reporter expression or some other factor. A recent study described the prediction of transcriptional noise based on intracellular physical distance between a regulator (XylS) and the target promoter $(\mathrm{Pm})^{31}$. By random mutagenesis and computational modeling, we identified position 117 in the active pocket of NitR as a critical site for sensitive ligand detection in GESS (Fig. 3d). Wild-type NitR showed a slightly longer distance between $\varepsilon$ caprolactam docked in the active site and the side chain of L117 than did the L117F mutant, suggesting that an aromatic amino acid with a bulky functional group at position 117 favors $\varepsilon$ caprolactam detection.

In this study, we applied CL-GESS to a metagenomic library derived from sea tidal flat sediments to identify enzymes that produce lactam from $\omega$-amino fatty acids. The resulting isolate, $\mathrm{CF} 3 \mathrm{HBD}$ is a unique biocatalyst with lactam-synthesizing activity as promiscuous activity that does not require a cofactor or energy source in an in vitro system (Fig. 5a). Along with the CF3HBD, other $3 \mathrm{HBD}$ enzymes with high sequence similarity also exhibited the cyclization activity towards 6-ACA (Supplementary Fig. 10). Here, we report an enzyme that can produce $\varepsilon$-caprolactam from 6-ACA identified using metagenomic library screening rather 


\begin{tabular}{|c|c|}
\hline \multicolumn{2}{|l|}{ CF3HBD-NAD $^{+}$} \\
\hline \multicolumn{2}{|l|}{ Data collection } \\
\hline Space group & $\mathrm{P} 2_{1}$ \\
\hline \multicolumn{2}{|l|}{ Cell dimensions } \\
\hline$a, b, c(\AA)$ & $62.5,148.3,62.4$ \\
\hline$\alpha, \beta, \gamma\left({ }^{\circ}\right)$ & $90,101.5,90$ \\
\hline Resolution $(\AA)^{a}$ & $50-2.29(2.33-2.29)$ \\
\hline$R_{\mathrm{sym}}(\%)$ & $11.8(89.1)$ \\
\hline$|/ \sigma|$ & $28.9(2.4)$ \\
\hline$R_{\text {meas }}(\%)$ & $12.8(96.8)$ \\
\hline$R_{\text {pim }}(\%)$ & $4.9(37.2)$ \\
\hline Completeness (\%) & $91.8(82.3)$ \\
\hline Redundancy & $6.8(6.0)$ \\
\hline \multicolumn{2}{|l|}{ Refinement } \\
\hline Resolution $(\AA)$ & $30.61-2.28$ \\
\hline No. reflections & 46,375 \\
\hline$R_{\text {work }} / R_{\text {free }}(\%)$ & $19.69 / 26.94$ \\
\hline No. of atoms & 7708 \\
\hline Protein & 7552 \\
\hline Ligand & 88 \\
\hline Water & 68 \\
\hline Average $B$-factors & 56.84 \\
\hline Wilson $B$-factor $\left(A^{2}\right)$ & 43.4 \\
\hline \multicolumn{2}{|l|}{ RMS deviations } \\
\hline Bond lengths $(\AA)$ & 0.008 \\
\hline Bond angles $\left(^{\circ}\right)$ & 1.072 \\
\hline \multicolumn{2}{|l|}{ Ramachandran plot } \\
\hline Favored (\%) & 96.1 \\
\hline Allowed (\%) & 3.6 \\
\hline Outliers (\%) & 0.3 \\
\hline
\end{tabular}

avalues in parentheses are for highest-resolution shell

\begin{tabular}{|c|c|c|c|c|}
\hline & \multicolumn{2}{|c|}{ 3-Hydroxybutyric acid } & \multicolumn{2}{|c|}{ 6-Aminocaproic acid } \\
\hline & $\begin{array}{l}\text { Specific } \\
\text { activity } \\
\text { (U/mg) }\end{array}$ & $\begin{array}{l}\text { Relative } \\
\text { activity (\%) }\end{array}$ & $\begin{array}{l}\text { Specific } \\
\text { activity } \\
\text { (U/mg) }\end{array}$ & $\begin{array}{l}\text { Relative } \\
\text { activity (\%) }\end{array}$ \\
\hline$\overline{W T}$ & $79.2 \pm 2.5$ & $100.0 \pm 3.2$ & $2.1 \pm 0.0$ & $100.0 \pm 0.3$ \\
\hline Q91A & $-a$ & - & - & - \\
\hline Q91E & $90.9 \pm 2.3$ & $114.9 \pm 2.9$ & $2.9 \pm 0.1$ & $139.5 \pm 6.4$ \\
\hline S139A & - & - & - & - \\
\hline V140A & - & - & $1.7 \pm 0.1$ & $83.2 \pm 4.3$ \\
\hline $\mathrm{H} 141 \mathrm{~A}$ & - & - & - & - \\
\hline $\mathrm{H} 141 \mathrm{E}$ & $0.9 \pm 0.03$ & $1.1 \pm 0.04$ & $1.2 \pm 0.0$ & $56.0 \pm 0.7$ \\
\hline K149A & $7.1 \pm 0.4$ & $8.9 \pm 0.5$ & $1.8 \pm 0.1$ & $88.0 \pm 4.8$ \\
\hline K149E & $23.5 \pm 0.3$ & $29.7 \pm 0.4$ & $1.6 \pm 0.0$ & $76.5 \pm 5.0$ \\
\hline Y152A & - & - & $6.5 \pm 0.5$ & $312.9 \pm 23.2$ \\
\hline Y152E & $28.5 \pm 1.3$ & $36.0 \pm 1.6$ & $2.1 \pm 0.7$ & $101.5 \pm 3.5$ \\
\hline W184A & - & - & $1.7 \pm 0.2$ & $84.2 \pm 7.5$ \\
\hline W184E & - & - & $1.8 \pm 0.1$ & $88.0 \pm 4.0$ \\
\hline W189A & $16.4 \pm 0.5$ & $20.8 \pm 0.7$ & $2.2 \pm 0.0$ & $106.6 \pm 1.3$ \\
\hline V190A & $77.7 \pm 3.6$ & $98.2 \pm 4.6$ & $1.8 \pm 0.1$ & $86.0 \pm 4.7$ \\
\hline Q193A & $14.6 \pm 0.2$ & $18.4 \pm 0.3$ & $1.0 \pm 0.0$ & $50.0 \pm 1.8$ \\
\hline Q193E & $168.1 \pm 5.8$ & $212.4 \pm 7.4$ & $2.6 \pm 0.2$ & $127.5 \pm 7.2$ \\
\hline
\end{tabular}

aNo activity at the specified assay conditions

than through a sequence search. For example, enzymes that convert 6-ACA to $\varepsilon$-caprolactam in the presence of a cofactor or energy source, such as acyl-CoA ligase and $\beta$-alanine CoAtransferase, have been identified by sequence searches based on broad substrate specificity ${ }^{11,12}$. In this study, 3-hydroxyacyl-CoA dehydrogenase, acetyl-CoA acetyltransferase, succinyl-CoA:3ketoacid-CoA transferase, and 3-oxoacid CoA-transferase were also obtained as hits from the metagenomic library screen, suggesting that CL-GESS is sufficiently sensitive to detect low or promiscuous activity. We also developed ACA-GESS, which included CL-GESS ${ }_{\mathrm{L} 117 \mathrm{~F}}$ and CF3HBD to detect $\omega$-amino fatty acids, such as 5-AVA and 6-ACA, via lactam formation. Thus, we could screen new enzymes using the CL-GESS sensor and apply the results to build another sensor, ACA-GESS. The screening systems presented here are powerful tools for investigating biocatalysts in unknown pathways.

We determined the crystal structure of CF3HBD in complex with $\mathrm{NAD}^{+}$at a resolution of $2.29 \AA$ to gain insight into its cyclase function. However, the crystal structure of CF3HBD in complex with $\varepsilon$-caprolactam or 6-ACA under various conditions could not obtain diffraction data in spite of various attempts. To identify critical active-site residues and understand the mechanism of $\omega$-amino fatty acid cyclization, we performed mutational analysis based on docking study of 6-ACA to the crystal structure of $\mathrm{CF} 3 \mathrm{HBD}$ in complex with $\mathrm{NAD}^{+}$. Alanine substitution mutants of 10 residues located within $4.0 \AA$ of the center of the docked 6-ACA in the crystal structure were studied. Among them, the mutant enzymes of Q91, S139, and H141 completely lost catalytic activities towards 3-hydroxybutyric acid (for dehydrogenation) and 6-ACA (for cyclization), suggesting that both activities share the catalytic site (Table 2).

According to previous reports, enzymatic amide bond formation for lactam synthesis requires the carboxylic group activation. Either ATP or acetyl-CoA acts as an activating molecule to synthesize lactams from $\omega$-amino acids in acyl-CoA ligase ${ }^{11,12}$. Alternatively, CALB lipase catalyzes the amide bond formation for lactam synthesis in organic solvent by transacylation by the active site residues ${ }^{16}$. The mechanism involves a nucleophilic serine in many esterases/lipases of the $\alpha / \beta$ hydrolase fold superfamily ${ }^{32,33}$. Coincidentally, the $\mathrm{S} 139$ residue of CF3HBD was estimated to be in close proximity to the substrate carboxylic group, allowing the enzyme to catalyze the opening of the cyclic amide group in $\varepsilon$-caprolactam, thereby generating 6 -ACA as a reaction product, but this activity is very low compared with the cyclization activity (Supplementary Fig. 14). Based on previous reports, the best possible explanation for this finding is the transacylation mechanism but in our best knowledge. Therefore, the cyclization of CF3HBD may follow steps similar to those in the transacylation reaction, as proposed in the reaction scheme in Supplementary Fig. 18. The carboxyl group of the substrate is likely to be activated by the S139 residue acting as a nucleophile, similar to that in other ester-transferase or amide-transferase. This means that S139 and H141 can act together to generate a nucleophile that attacks the carbonyl group to activate the carboxylic group of 6-ACA, while Q91 may form hydrogen bonds with the oxygen of the carbonyl group in 6-ACA (Supplementary Fig. 19). To understand the cyclization activity of CF3HBD in detail, the structure of mutant enzymes with the substrate molecule inside the active site has to be solved. Furthermore, the mechanism of cyclization by CF3HBD needs to be studied in more detail.

In conclusion, we firstly established and engineered a lactamdetecting biosensor (CL-GESS) with high sensitivity and specificity. Using this biosensor, we then screened diverse metagenomes and successfully identified a cyclase that converts 6-ACA to $\varepsilon$ caprolactam. Finally, we determined the X-ray crystal structure of the cyclase to provide insight into its cyclization activity and clarified the active-site residues by mutational study. Using the cyclase found in this study, we next developed a genetically encoded biosensor to sense $\omega$-amino fatty acids (5-ACA or 6- 
Table 3 Kinetic parameters of the wild-type and Y152A mutant enzymes toward 6-aminocaproic acid

\begin{tabular}{lll} 
& Wild type & Y152A \\
\hline$K_{\mathrm{m}}(\mathrm{mM})$ & $3.3 \pm 0.3$ & $2.9 \pm 0.1$ \\
$k_{\text {cat }}\left(\mathrm{min}^{-1} \times 10^{-3}\right)$ & $72.2 \pm 2.0$ & $208.5 \pm 1.6$ \\
$k_{\text {cat }} / K_{\mathrm{m}}\left(\mathrm{min}^{-1} \mathrm{M}^{-1}\right)$ & $21.8 \pm 1.8$ & $73.1 \pm 2.1$ \\
\hline
\end{tabular}

AVA). Consequently, our CL-GESS could prove a powerful tool for the development of a bioprocess to produce lactams and nylons.

\begin{abstract}
Methods
Materials. All chemical reagents used in this study were purchased from SigmaAldrich (St. Louis, MO, USA). Restriction endonucleases, DNA cloning kits, pUC19 plasmid, and E. coli DH5a cells were purchased from New England Biolabs (Ipswich, MA, USA). The Diversify PCR Random Mutagenesis kit and QuikChange II XL Site-Directed Mutagenesis kit were purchased from Clontech (Mountain View, CA, USA) and Agilent Technologies (San Diego, CA, USA), respectively. Plasmid DNA isolation and DNA extraction were conducted using plasmid preparation kits (Promega, Madison, WI, USA). Oligonucleotides (Supplementary Table 5) were synthesized and sequenced by Macrogen (Daejeon, Korea).
\end{abstract}

Construction of the CL-GESS plasmid. We designed an $\varepsilon$-caprolactam detection system consisting of the TR NitR, a NitA promoter, and GFP as a reporter protein. nitR and the nitA promoter fragments were amplified by PCR from the genomic DNA of A. faecalis JM3 KCTC2687 (ATCC8750) using primer pairs 1/2 and 3/4, respectively (Supplementary Table 5). nitR was subcloned downstream of the constitutively active promoter $J 23016$ (from http://parts.igem.org), and nitA was inserted on the opposite side of nitR to avoid transcriptional noise. The egfp gene from the plasmid $\mathrm{pMGFP}^{34}$ was subcloned downstream of the nitA promoter. The transcription terminator rrnBT1T2 from plasmid pHCEIIB and tL3 from plasmid pKD46 were inserted into the C-termini of egfp and nitR by overlap PCR. The CLGESS plasmid was constructed by ligating the DNA fragment into plasmid pUC19 for $E$. coli, $\mathrm{pBBRBB}^{20}$ for $P$. putida KT2440, and pSEVA $234^{35}$ for $R$. eutropha. We also switched the fluorescent reporter to the $s f g f p^{36}$ gene to increase the sensitivity of the assay. In order to increase the sensitivity of CL-GESS for $\varepsilon$-caprolactam, we generated various synthetic promoters and RBS for nit $R$ transcription by PCR and subcloned these into CL-GESS (Supplementary Table 5). To investigate the NitRbinding site and mechanisms of transcription, truncated promoter fragments concatenated to the $g f p$ reporter gene were generated and subcloned into CL-GESS (Supplementary Table 5).

Identification of the transcription start site in $\boldsymbol{P}_{\text {nita }}$. Total RNA was extracted from CL-GESS cells cultured with $10 \mathrm{mM} \varepsilon$-caprolactam using the Eastep Super Total RNA Extraction kit (Promega). cDNA was synthesized using the SMARTer RACE cDNA Amplification kit (Clontech). The transcription start site was identified using the Switching Mechanism at the $5^{\prime}$ end of RNA transcript (SMART) RACE cDNA Amplification kit (Clontech) following the manufacturer's protocol. Two reverse gene-specific primers (GSPs) for amplifying sfgfp in CL-GESS were designed, including sfgfp-GSP1, which binds the ORF $605 \mathrm{bp}$ downstream of the ATG (5'-tctgctgataatgatctgccagctgca) and was used with the universal primer mix to target the SMART sequence at the $5^{\prime}$ end of the cDNA; and sfgfp-GSP2, located 190 bp downstream of the ATG (5'-aaacactgaacgccataggtca). RACE products were visualized on a $2 \%$ agarose gel and were purified using the Wizard SV Gel and PCR Clean-Up System (Promega) according to the manufacturer's protocol. DNA sequencing was performed by Macrogen.

Mutagenesis of NitR and 3HBD. A NitR mutant library was constructed by errorprone PCR using a PCR mutagenesis kit with a mutation rate of 2-4 mutations per 1000 base pairs and using CL-GESS as a template. Fragments used to construct the mutant library were prepared by standard PCR and were ligated into the genetic circuit using the Gibson Assembly Master Mix (New England Biolabs). NitR mutants (S133P, L117F, L117A, L117E, L117Q, L117R, L117W, and L117Y) and 3HBD mutants (Q91A, Q91E, S139A, S139E, V140A, V140E, H141A, H141E, K149A, K149E, Y152A, Y152E, Q193A, Q193E, Q193E, W184A, W184E, and V190A) were generated using the QuikChange II XL Site-Directed Mutagenesis kit and a primer pair (Supplementary Tables 6 and 7). Reactions were carried out under conditions specified by the manufacturer. DNA sequencing was performed by Macrogen.
Mutant library construction and NitR screening. E. coli DH5a cells were transformed by electroporation with ligation mixtures containing mutant genes. Transformants were spread on LB agar plates containing $100 \mu \mathrm{g} / \mathrm{ml}$ ampicillin and were incubated at $37^{\circ} \mathrm{C}$ for $16 \mathrm{~h}$. The library $\left(\right.$ size: $4 \times 10^{5}$ ) was stored at $-70^{\circ} \mathrm{C}$ in storage buffer ( $1 \times \mathrm{TY}$ consisting of $8 \mathrm{~g}$ tryptone, $5 \mathrm{~g}$ yeast extract, and $2.5 \mathrm{~g} \mathrm{NaCl}$ in 11 of distilled water) containing $15 \%$ (v/v) glycerol until screening by flow cytometry with a FACSAria III instrument (BD Biosciences, Franklin Lakes, NJ, USA). The library $\left(5.6 \times 10^{6}\right.$ cells) was inoculated in $2 \mathrm{ml}$ of LB medium containing 100 $\mu \mathrm{M} \varepsilon$-caprolactam and $100 \mu \mathrm{g} / \mathrm{ml}$ ampicillin and incubated at $37^{\circ} \mathrm{C}$ for $4 \mathrm{~h}$ prior to flow cytometry. A blue laser $(488 \mathrm{~nm})$ and bandpass filter $(530 / 30 \mathrm{~nm})$ were used to analyze fluorescence intensity of the mutant library. Approximately 20,000 cells with high fluorescence intensity (top $0.4 \%$ ) in $5.6 \times 10^{6}$ cells were collected and were recovered in $\mathrm{LB}$ medium at $37^{\circ} \mathrm{C}$ for $16 \mathrm{~h}$. In the second round of screening, false-positive cells showing high fluorescence intensity in the absence of $\varepsilon$ caprolactam were removed by sorting non-fluorescent cells. Approximately $1.5 \times$ $10^{5}$ (bottom $3 \%$ ) non-fluorescent cells in $3 \times 10^{6}$ negatively sorted cells were collected and were grown in LB medium. In the third round, 1000 fluorescent cells with the highest fluorescence in $2 \times 10^{6}$ (top $0.1 \%$ ) in the presence of $100 \mu \mathrm{M} \varepsilon$ caprolactam were sorted and were grown on LB agar, and a single clone exhibiting higher fluorescence intensity than cells expressing wild-type NitR was selected for further examination.

NitR structure modeling and docking simulations. Homology modeling of $A$. faecalis NitR was carried out using Discovery Studio 3.1 (Accelrys, San Diego, CA, USA) based on the X-ray structure of ToxT. Homology searches and sequence alignment were conducted using sequence analysis and multiple sequence alignment modules, respectively. Five models were generated based on the alignment of the target sequence with its template using the MODELLER software program ${ }^{37}$ by applying the default model-building routine model with fast refinement. The advantages of this procedure are that it allows selection of the best model from among several candidates and that variability among models can be used to evaluate model reliability. Energy minimization was applied using a consistent valence force field and DS CHARMm with the steepest descent and conjugated gradient algorithms. The quality of the models was analyzed with the PROCHECK software ${ }^{38}$. $\varepsilon$-Caprolactam was docked as the ligand in the NitR model using AutoDock Vina ${ }^{39}$. Docking pocket residues were searched using the Pck pocket detection program (http://schwarz.benjamin.free.fr/Work/Pck/home.htm). The lowest energy conformation was selected for further analyses.

Fluorescence analysis. E. coli DH5a cells harboring CL-GESS and CL-GESS mutants were grown on LB agar containing $100 \mu \mathrm{g} / \mathrm{ml}$ ampicillin and various substrates including $\varepsilon$-caprolactam, L-lysine, and 6 -ACA at $37^{\circ} \mathrm{C}$ for $16 \mathrm{~h}$. Fluorescent colonies were visualized with an epifluorescence microscope (AZ100-M; Nikon, Tokyo, Japan) equipped with a GFP filter (excitation: $455-485 \mathrm{~nm}$; emission: $500-545 \mathrm{~nm}$ ). For CL-GESS fluorescence analysis in the liquid phase, single colonies harboring CL-GESS and CL-GESS mutants were inoculated in $2 \mathrm{ml}$ of LB medium with $100 \mu \mathrm{g} / \mathrm{ml}$ ampicillin. After cultivation at $37^{\circ} \mathrm{C}$ for $8 \mathrm{~h}, 1 \%(\mathrm{v} / \mathrm{v})$ of the seed culture was inoculated in $2 \mathrm{ml}$ of fresh LB with various concentrations of $\varepsilon$-caprolactam $(500 \mu \mathrm{M}-30 \mathrm{mM})$, as well as other chemicals $(1 \mathrm{mM})$ to test ligand specificity. For ACA-GESS fluorescence analysis in the liquid phase, single colonies of E. coli EPI300 (DE3) harboring CL-GESS ${ }_{\mathrm{L} 117 \mathrm{~F}}$ and CF3HBD in pET28a $(+)$ were inoculated in $2 \mathrm{ml}$ of $\mathrm{LB}$ medium with $100 \mu \mathrm{g} / \mathrm{ml}$ ampicillin and $25 \mathrm{~g} / \mathrm{ml} \mathrm{kana-}$ mycin. After cultivation at $37^{\circ} \mathrm{C}$ for $8 \mathrm{~h}, 1 \%$ (v/v) of the seed culture was inoculated in $2 \mathrm{ml}$ of fresh $\mathrm{LB}$ containing ampicillin and kanamycin along with $0.1 \mathrm{mM}$ isopropyl $\beta$-D-1-thiogalactopyranoside (IPTG) and various concentrations of $\omega$-amino fatty acids (5-AVA acid and 6-ACA). Fluorescence intensity was measured after 16 $\mathrm{h}$ at $37^{\circ} \mathrm{C}$ on a multi-label microplate reader (PerkinElmer, Waltham, MA, USA) at excitation and emission wavelengths of 485 and $535 \mathrm{~nm}$, respectively. Cells were sorted on a FACSCalibur instrument (BD Biosciences), and the data were analyzed using the FlowJo software (Tree Star, Ashland, OR, USA).

Metagenomic library screening by CL-GESS and cyclase. Metagenomic DNA was isolated from ocean flat tidal sediments on the west coast of Korea (Taean Korea) using a hydroshear GeneMachine (Genomic Instrumentation Services, Foster City, CA, USA). A metagenomic DNA fosmid library was constructed in $E$. coli EPI300 cells harboring fosmid pCC1FOS using a Copy Control Fosmid Library Production kit (Epicentre, Madison, WI, USA) according to the manufacturer's protocol. For functional screening of cyclase, E. coli EPI300 cells harboring the metagenomic library were electrophoretically transformed with the CL-GESS plasmid and were grown on LB agar containing $50 \mathrm{mM} 6-\mathrm{ACA}, 100 \mu \mathrm{g} / \mathrm{ml}$ ampicillin, and $34 \mu \mathrm{g} / \mathrm{ml}$ chloramphenicol at $37^{\circ} \mathrm{C}$ for $14 \mathrm{~h}$. The fluorescence intensity of colonies was evaluated by fluorescence microscopy, and colonies with strong signals were selected and were incubated in LB medium containing $50 \mathrm{mM}$ 6-ACA for $24 \mathrm{~h}$ at $37^{\circ} \mathrm{C}$ for subsequent screening. Fluorescence intensity was measured with a FACSCalibur instrument (excitation: $488 \mathrm{~nm}$; emission $=530 / 30$ $\mathrm{nm})$ and data were analyzed with FlowJo.

Cyclase purification and LC-MS analysis. After screening, the putative cyclase gene $(C F 3 H B D)$ was amplified from the metagenomic hit and cloned into the 
pET28a $(+)$ plasmid, yielding plasmid pET28a-cyclase harboring an N-terminal $6 \times$ His-tag (Supplementary Table 8). Sufficiently strong expression of CF3HBD was achieved in E. coli without codon optimization and the enzyme could be purified at a high yield as shown in Supplementary Fig. 10a. To measure cyclase activity, $E$. coli $\mathrm{C} 2566$ cells harboring pET28a(+)-cyclase were grown in LB medium at $37^{\circ} \mathrm{C}$ until they reached an optical density at $600 \mathrm{~nm}$ of $0.4-0.5$. The cells were then induced with $0.1 \mathrm{mM}$ IPTG. The culture was transferred to a $20^{\circ} \mathrm{C}$ incubator for $18 \mathrm{~h}$, harvested by centrifugation at $3000 \mathrm{rpm}$ for $10 \mathrm{~min}$, and resuspended in lysis buffer $\left(300 \mathrm{mM} \mathrm{KCl}, 50 \mathrm{mM} \mathrm{KH}_{2} \mathrm{PO}_{4}, 5 \mathrm{mM}\right.$ imidazole, $\mathrm{pH}$ 8.0). Cell extracts were prepared by sonication and purified with the Profinia" Protein Purification System (Bio-Rad, Hercules, CA, USA), which is configured for automated His-tag affinity chromatography with optional integrated desalting. The final fraction was eluted with $50 \mathrm{mM}$ HEPES buffer (pH 7.5) and was used as a purified enzyme. Protein was quantified by the Bradford method. The purified proteins were confirmed by SDS-PAGE

Measurement of activity and kinetic parameters. The dehydrogenation activity of CF3HBD was determined based on NADH formation from NAD, by measuring the absorbance at $340 \mathrm{~nm}$. The enzymatic reaction was carried out in $50 \mathrm{mM}$ HEPES (pH 7.5) containing $5 \mathrm{mM}$ 3-hydroxybutyric acid, and $10 \mathrm{mM} \mathrm{NAD}$ at $40^{\circ}$ $\mathrm{C}$ for $10 \mathrm{~min}$. One unit (U) of CF3HBD dehydrogenation activity was defined as the amount of enzyme that catalyzes the reduction of $1 \mu \mathrm{mol}$ of NAD per min at $40^{\circ} \mathrm{C}$ and $\mathrm{pH}$ 8.0. For CF3HBD cyclization activity, $1 \mathrm{mM}$ 6-ACA in $50 \mathrm{mM}$ HEPES ( $\mathrm{pH}$ 7.5) was reacted at $35^{\circ} \mathrm{C}$ for $10 \mathrm{~min}$. One unit (U) of CF3HBD cyclization activity was defined as the amount of enzyme required to produce 1 nmol of $\varepsilon$-caprolactam per min at $35^{\circ} \mathrm{C}$ and $\mathrm{pH} 7.5$. To examine the effect of $\mathrm{pH}$ on the activity of $3 \mathrm{HBD}$, the $\mathrm{pH}$ was varied between 6.5 and 8.5 using $50 \mathrm{mM}$ piperazine- $N, N^{\prime}$-bis(2-ethanesulfonic acid) buffer ( $\mathrm{pH}$ 6.5-7.5) and $50 \mathrm{mM}$ HEPES buffer ( $\mathrm{pH} 7.5-8.5$ ). To investigate the effect of temperature on the enzyme activity, the temperature was varied from 25 to $55^{\circ} \mathrm{C}$. Metal ion-treated enzyme was prepared by adding $0.5 \mathrm{mM}$ metal ion, including $\mathrm{Ba}^{2+}, \mathrm{Ca}^{2+}, \mathrm{Cu}^{2+}, \mathrm{Fe}^{2+}, \mathrm{Mg}^{2+}, \mathrm{Mn}^{2}$ ,$+ \mathrm{Ni}^{2+}$, or $\mathrm{Zn}^{2+}$ to the purified CF3HBD enzyme after treatment with $10 \mathrm{mM}$ EDTA, followed by dialysis against $50 \mathrm{mM}$ HEPES ( $\mathrm{pH} 7.5)$ at $4{ }^{\circ} \mathrm{C}$ for $16 \mathrm{~h}$. The enzyme activity was assayed with $1 \mathrm{mM} 6-\mathrm{ACA}$ in in $50 \mathrm{mM}$ HEPES (pH 7.5) containing $1 \mathrm{mM}$ metal ion at $35^{\circ} \mathrm{C}$ for $10 \mathrm{~min}$. In the kinetics study, various amounts of 6-ACA $(0.1-20 \mathrm{mM})$ were incubated in $50 \mathrm{mM}$ HEPES (pH 7.5) containing purified $3 \mathrm{HBD}$ enzyme at $35^{\circ} \mathrm{C}$ for $10 \mathrm{~min}$. The reaction was stopped by the addition of $\mathrm{HCl}$ at a final concentration of $200 \mathrm{mM}$. The values of the enzyme kinetic parameters $K_{\mathrm{m}}$ and $k_{\text {cat }}$ for substrates were determined by fitting the data to the Michaelis-Menten equation.

Analytical methods. $\varepsilon$-Caprolactam and 6-ACA contents in the reaction mixture were determined by LC-MS using an instrument fitted with an Eclipse XDB-C18 column $(4.6 \times 150 \mathrm{~mm}$; Agilent Technologies, Santa Clara, CA, USA), with a mobile phase consisting of an acetonitrile/1\% formic acid $(10: 90 \mathrm{v} / \mathrm{v})$ gradient from $10 \%$ to $90 \%$ at $25^{\circ} \mathrm{C}$. The eluent was directed to MS using ESI-positive ion mode with following conditions: fragmentor, $70 \mathrm{~V}$; drying gas flow, $12.0 \mathrm{~L} / \mathrm{min}$; drying gas temperature, $350{ }^{\circ} \mathrm{C}$; nebulizer pressure, $35 \mathrm{psig}$; capillary voltage, $2.5 \mathrm{kV}$. The scan mode was used and scanned mass range was $m / z 50-200 \mathrm{kDa}$. The flow rate was $0.4 \mathrm{ml} / \mathrm{min}$, and retention times of 6-ACA and $\varepsilon$-caprolactam were 3.7 and 8.3 min, respectively. The structure of $\varepsilon$-caprolactam confirmed by $700 \mathrm{MHz}{ }^{1} \mathrm{H}$ NMR analysis at the Korea Basic Science Institute (Ochang, Korea) and Infrared (IR) Spectrometer (Bruker EQUINOX 55 FT-IR Spectrometer) at the Korea Research Institute of Chemical Technology (Daejon, Korea), respectively. To confirm the $\varepsilon$ caprolactam from the enzyme reaction solution, ethyl actate extraction method as mentioned below was used. The residue after evaporation was reconstituted with 1/ 10 volume of water and analyzed by NMR and IR.

To determine the intracellular level of $\varepsilon$-caprolactam, the cultivation at $37{ }^{\circ} \mathrm{C}$ for $16 \mathrm{~h}, 1 \%(\mathrm{v} / \mathrm{v})$ of the seed culture of CLGESS-harboring E. coli DH5a cells were performed in $100 \mathrm{ml}$ of fresh LB with various concentrations of $\varepsilon$-caprolactam (1, 10 , and $30 \mathrm{mM})$. And $50-100 \mathrm{mg}$ wet were washed with $50 \mathrm{ml}$ of saline buffer $(1000$ times the volume of cells), and then resuspended in $300 \mu \mathrm{l}$ of $20 \%$ trichloroacetic acid to completely degrade the cell membranes. The samples were vortexed for 1 $\mathrm{min}$, incubated on ice for $2 \mathrm{~h}$, and centrifuged at $12,000 \times g$ at $4^{\circ} \mathrm{C}$ for $10 \mathrm{~min}$. The supernatant was collected and mixed with an equal volume of ethyl acetate by vortexing for $10 \mathrm{~min}$. The mixture was centrifuged for $10 \mathrm{~min}$, and the supernatant was transferred to new tube. The ethyl acetate was removed from the extracts by using a rotary evaporator. The residue was reconstituted in an equal volume of PBS buffer and analyzed by LC-MS. To compare extraction efficiencies, we simultaneously extracted a standard of $\varepsilon$-caprolactam.

Crystallization and structure determination. Crystals of the $\mathrm{CL}$ synthase-NAD ${ }^{+}$ complex were grown at $20^{\circ} \mathrm{C}$ using the hanging-drop vapor diffusion method by mixing $2 \mu \mathrm{l}$ of protein solution containing $5 \mathrm{mM} \mathrm{NAD}^{+}$and $2 \mu \mathrm{l}$ of crystallization buffer with $3.2 \mathrm{M}$ sodium acetate ( $\mathrm{pH} 6.5)$. Diffraction data were collected at $-170^{\circ}$ $\mathrm{C}$ using $30 \%(\mathrm{w} / \mathrm{v})$ glycerol as a cryoprotectant. Crystals belonging to space group $\mathrm{P} 2{ }_{1}$, had dimensions $a=62.470 \AA, b=148.259 \AA$, and $c=62.382 \AA$, and contained four molecules in an asymmetric unit. Diffraction data from native crystals were collected using a synchrotron X-ray source at $0.97931 \AA$ on beamline 7A at the Pohang Advanced Light Source (Pohang, South Korea). Datasets were processed using the HKL2000 program. The crystal structure was determined by molecular replacement using the PhaserMR program in the CCP4 software suite ${ }^{40}$. The $P$. putida D-3-hydroxybutyrate dehydrogenase (PDB ID 2Q2Q) sequence was processed using Chainsaw in the CCP4 suite according to the corresponding sequence of the CF3HBD, and was then employed as the search model for CF3HBD ${ }^{41}$. The sequence identity of CF3HBD and PP3HBD is $70.31 \%$. Crystallographic refinement was carried out with PHENIX ${ }^{41}$, and model building was performed using COOT $^{42}$

\section{Data availability}

The refined models of CF3HBD have been deposited in the Protein Data Bank (https://www.rcsb.org/structure/5YSS) with PDB code 5YSS. All data that support the findings of this study are included in this article and in Supplementary Information. They are available from the corresponding author upon reasonable request. A reporting summary for this article is available as a Supplementary Information file.

Received: 25 October 2017 Accepted: 1 November 2018

Published online: 29 November 2018

\section{References}

1. Xiong, D. et al. Improving key enzyme activity in phenylpropanoid pathway with a designed biosensor. Metab. Eng. 40, 115-123 (2017).

2. Mahr, R. \& Frunzke, J. Transcription factor-based biosensors in biotechnology: current state and future prospects. Appl. Microbiol. Biotechnol. 100, 79-90 (2016).

3. Kim, H. et al. A cell-cell communication-based screening system for novel microbes with target enzyme activities. ACS Synth. Biol. 5, 1231-1238 (2016).

4. Eggeling, L., Bott, M. \& Marienhagen, J. Novel screening methodsbiosensors. Curr. Opin. Biotechnol. 35, 30-36 (2015).

5. Schallmey, M., Frunzke, J., Eggeling, L. \& Marienhagen, J. Looking for the pick of the bunch: high-throughput screening of producing microorganisms with biosensors. Curr. Opin. Biotechnol. 26, 148-154 (2014).

6. Raman, S., Rogers, J. K., Taylor, N. D. \& Church, G. M. Evolution-guided optimization of biosynthetic pathways. Proc. Natl Acad. Sci. USA 111, 17803-17808 (2014)

7. Choi, S. L. et al. Toward a generalized and high-throughput enzyme screening system based on artificial genetic circuits. ACS Synth. Biol. 3, 163-171 (2014).

8. Van Rossum, T., Kengen, S. W. \& Van der Oost, J. Reporter-based screening and selection of enzymes. FEBS J. 280, 2979-2996 (2013).

9. Helm, Evd, Genee, H. J. \& Sommer, M. O. A. The evolving interface between synthetic biology and functional metagenomics. Nat. Chem. Biol. 14, 752-759 (2018)

10. Tang, S. Y., Fazelinia, H. \& Cirino, P. C. AraC regulatory protein mutants with altered effector specificity. J. Am. Chem. Soc. 130, 5267-5271 (2008).

11. Zhang, J. et al. Application of an Acyl-CoA ligase from Streptomyces aizunensis for lactam biosynthesis. ACS Synth. Biol. 6, 884-890 (2017)

12. Chae, T. U., Ko, Y. S., Hwang, K. S. \& Lee, S. Y. Metabolic engineering of Escherichia coli for the production of four-, five- and six-carbon lactams. Metab. Eng. 41, 82-91 (2017).

13. Thomas, J. M. \& Raja, R. Design of a "green" one-step catalytic production of epsilon-caprolactam (precursor of nylon-6). Proc. Natl Acad. Sci. USA 102, 13732-13736 (2005).

14. Beerthuis, R., Rothenberg, G. \& Shiju, N. R. Catalytic routes towards acrylic acid, adipic acid and $\varepsilon$-caprolactam starting from biorenewables. Green Chem. 17, 1341-1361 (2015).

15. Turk, S. C. et al. Metabolic engineering toward sustainable production of nylon-6. ACS Synth. Biol. 5, 65-73 (2016).

16. Stavila, E. \& Loos, K. Synthesis of lactams using enzyme-catalyzed aminolysis. Tetrahedron Lett. 54, 370-372 (2013).

17. Komeda, H., Hori, Y., Kobayashi, M. \& Shimizu, S. Transcriptional regulation of the Rhodococcus rhodochrous J1 nitA gene encoding a nitrilase. Proc. Natl Acad. Sci. USA 93, 10572-10577 (1996).

18. Strohl, W. R. Compilation and analysis of DNA sequences associated with apparent streptomycete promoters. Nucleic Acids Res. 20, 961-974 (1992).

19. Nagasawa, T., Nakamura, T. \& Yamada, H. $\varepsilon$-caprolactam, a new powerful inducer for the formation of Rhodococcus rhodochrous J1 nitrilase. Arch. Microbiol. 155, 13-17 (1990).

20. Vick, J. E. et al. Optimized compatible set of BioBrick vectors for metabolic pathway engineering. Appl. Microbiol. Biotechnol. 92, 1275-1286 (2011). 
21. Loeschcke, A. \& Thies, S. Pseudomonas putida-a versatile host for the production of natural products. Appl. Microbiol. Biotechnol. 99, 6197-6214 (2015).

22. Lowden, M. J. et al. Structure of Vibrio cholerae ToxT reveals a mechanism for fatty acid regulation of virulence genes. Proc. Natl Acad. Sci. USA 107, 2860-2865 (2010).

23. Paithankar, K. S. et al. Cosubstrate-induced dynamics of D-3-hydroxybutyrate dehydrogenase from Pseudomonas putida. FEBS J. 274, 5767-5779 (2007).

24. Kim, Y. J. et al. Improved metagenome screening efficiency by random insertion of T7 promoters. J. Biotechnol. 230, 47-53 (2016).

25. Choi, S.-L. et al. Toward a generalized and high-throughput enzyme screening system based on artificial genetic circuits. ACS Synth. Biol. 3, 163-171 (2013).

26. Kwon, K. K. et al. Evolution of enzymes with new specificity by highthroughput screening using DmpR-based genetic circuits and multiple flow cytometry rounds. Sci. Rep. 8, 2659 (2018).

27. Jeong, Y. S. et al. High-throughput screening system based on phenolicsresponsive transcription activator for directed evolution of organophosphatedegrading enzymes. Protein Eng. Des. Sel. 25, 725-731 (2012).

28. Gallegos, M. T., Schleif, R., Bairoch, A., Hofmann, K. \& Ramos, J. L. Arac/XylS family of transcriptional regulators. Microbiol. Mol. Biol. Rev. 61, 393-410 (1997).

29. Brehm-Stecher, B. F. \& Johnson, E. A. Single-cell microbiology: tools, technologies, and applications. Microbiol. Mol. Biol. Rev. 68, 538-559 (2004).

30. Czechowska, K., Johnson, D. R. \& van der Meer, J. R. Use of flow cytometric methods for single-cell analysis in environmental microbiology. Curr. Opin. Microbiol. 11, 205-212 (2008).

31. Goñi-Moreno, Á., Benedetti, I., Kim, J. \& Lorenzo, V. D. Deconvolution of gene expression noise into spatial dynamics of transcription factor-promoter interplay. ACS Synth. Biol. 6, 1359-1369 (2017).

32. Goswami, A. \& Van Lanen, S. G. Enzymatic strategies and biocatalysts for amide bond formation: tricks of the trade outside of the ribosome. Mol. Biosyst. 11, 338-353 (2015).

33. Rauwerdink, A. \& Kazlauskas, R. J. How the same core catalytic machinery catalyzes 17 different reactions: the serine-histidine-aspartate catalytic triad of a/ $\beta$-hydrolase fold enzymes. ACS Catal. 5, 6153-6176 (2015).

34. Ha, J. S. et al. Design and application of highly responsive fluorescence resonance energy transfer biosensors for detection of sugar in living Saccharomyces cerevisiae cells. Appl. Environ. Microbiol. 73, 7408-7014 (2007).

35. Silva-Rocha, R. et al. The Standard European Vector Architecture (SEVA): a coherent platform for the analysis and deployment of complex prokaryotic phenotypes. Nucleic Acids Res. 41(Database issue), D666-D675 (2013).

36. Pedelacq, J. D., Cabantous, S., Tran, T., Terwilliger, T. C. \& Waldo, G. S. Engineering and characterization of a superfolder green fluorescent protein. Nat. Biotechnol. 24, 79-88 (2006).

37. Marti-Renom, M. A. et al. Comparative protein structure modeling of genes and genomes. Annu. Rev. Biophys. Biomol. Struct. 29, 291-325 (2000).

38. Laskowski, R. A., MacArthur, M. W., Moss, D. S. \& Thornton, J. M. PROCHECK: a program to check the stereochemical quality of protein structures. J. Appl. Crystallogr. 26, 283-291 (1993).

39. Trott, O. \& Olson, A. J. AutoDock Vina: improving the speed and accuracy of docking with a new scoring function, efficient optimization, and multithreading. J. Comput. Chem. 31, 455-461 (2010).

40. Winn, M. D. et al. Overview of the CCP4 suite and current developments. Acta Crystallogr. D D67, 235-242 (2011).
41. Adams, P. D. et al. PHENIX: a comprehensive Python-based system for macromolecular structure solution. Acta Crystallogr. D 66, 213-221 (2010).

42. Emsley, P. \& Cowtan, K. Coot: model-building tools for molecular graphics. Acta Crystallogr. D 60, 2126-2132 (2004).

\section{Acknowledgements}

This research was supported by grants from C1 Gas Refinery Program funded by the Ministry of Science and ICT (NRF-2018M3D3A1A01055732), the National Research Foundation of Korea (NRF) grant funded by the Korea government (MSIT) (2018R1A2B3004755), the Intelligent Synthetic Biology Center of the Global Frontier Project (2011-0031944), and the Korea Research Institute of Bioscience and Biotechnology Research Initiative Program.

\section{Author contributions}

S.J.Y. designed and performed experiments and wrote the manuscript. S.J.Y. and S.G.L. revised the manuscript and prepared it for submission. M.K., K.K.K., E.R., and performed gene construction and imaging experiments and analyzed data. Y.F. performed analysis of crystal structure and homology modeling. S.H.P. performed site-directed mutagenesis and purified enzymes for determination of active sites. H.L., H.K., D.H.L., and D.M.K. conceived the research and assisted in research design and data interpretation. S.G.L. conceived research, analyzed data, and wrote the manuscript. All authors reviewed the results and approved the manuscript.

\section{Additional information}

Supplementary Information accompanies this paper at https://doi.org/10.1038/s41467 018-07488-0.

Competing interests: The authors declare no competing interests.

Reprints and permission information is available online at http://npg.nature.com/ reprintsandpermissions/

Publisher's note: Springer Nature remains neutral with regard to jurisdictional claims in published maps and institutional affiliations.

\begin{abstract}
(c) (i) Open Access This article is licensed under a Creative Commons cc Attribution 4.0 International License, which permits use, sharing, adaptation, distribution and reproduction in any medium or format, as long as you give appropriate credit to the original author(s) and the source, provide a link to the Creative Commons license, and indicate if changes were made. The images or other third party material in this article are included in the article's Creative Commons license, unless indicated otherwise in a credit line to the material. If material is not included in the article's Creative Commons license and your intended use is not permitted by statutory regulation or exceeds the permitted use, you will need to obtain permission directly from the copyright holder. To view a copy of this license, visit http://creativecommons.org/ licenses/by/4.0/.
\end{abstract}

(C) The Author(s) 2018 